\title{
PENDAMPINGAN TEKNIK BUDIDAYA BUNGA TABUR DAN PEMBUATAN BIBIT TANAMAN HIAS DALAM RANGKA MENDUKUNG KAMPUNG PRODUKTIF DI DESA GESIK
}

\author{
Umi Trisnaningsih ${ }^{1}$, Siti Wahyuni ${ }^{1}$, dan Wachdijono ${ }^{2}$. \\ ${ }^{1}$ Program Studi Agroteknologi, Fak. Pertanian, Universitas Swadaya Gunug Jati (UGJ) \\ ${ }^{2}$ Program Studi Agribisnis, Fak. Pertanian, Universitas Swadaya Gunug Jati (UGJ) \\ E-mail: umitrisna@gmail.com
}

\begin{abstract}
ABSTRAK. Keberadaan petani bunga tabur di Desa Gesik semakin terdesak karena alih fungsi lahan dan munculnya pesaing dari wilayah lain. Kegiatan pengabdian ini bertujuan untuk memberikan alternatif usahatani lain yang tidak terlalu berbeda dari usahatani yang dilakukan saat ini. Metode yang digunakan dalam pelaksanaan program ini adalah pelatihan, yaitu penyuluhan dan praktek, serta pendampingan budidaya tanaman. Pelatihan yang dilaksanakan adalah pelatihan teknik budidaya dan perbanyakan tanaman hias. Selain itu juga dilakukan pendampingan dalam praktek perbanyakan tanaman hias. Untuk mengetahui tingkat keberhasilan pelaksanaan kegiatan pengabdian ini dilakukan survey terhadap peserta sebelum dan sesudah pelaksanaan kegiatan. hasil analisis Uji t berpasangan menunjukkan bahwa setelah pelaksanaan kegiatan ini, para petani mengetahui manfaat lain dari limbah hasil pangkasan yang dapat digunakan sebagai bahan setek untuk pembuatan bibit tanaman hias yang dapat dijual.
\end{abstract}

Kata kunci: bunga tabur; perbanyakan tanaman; diversifikasi usaha

\section{FARMING TECHNIQUE OF SOWING FLOWER AND MAKING ORNAMENTAL SEED ASSISTANCE IN SUPPORT PRODUCTIVE VILLAGES IN GESIK VILLAGE}

\begin{abstract}
The existence of farmers sowing flowers in the village of Gesik increasingly pressed because of the conversion of land and the emergence of competitors from other regions. This community service aims to provide alternative farming that is not too different from the current farming activities. The method used in the implementation of this program is training, namely counseling and practice, as well as mentoring for plant cultivation. The training carried out is training in cultivation techniques and propagation of ornamental plants. In addition, assistance was also made in the practice of propagation of ornamental plants. After the implementation of this activity, the farmers learned about other benefits of pruned waste that could be used as cuttings material for the production of ornamental seedlings for sale.
\end{abstract}

Keywords: business diversification; plant propagation; sowing flower.

\section{PENDAHULUAN}

Perkembangan suatu daerah seringkali menuntut masyarakatnya untuk berubah. Hal yang sama terjadi Desa Gesik, Kec. Tengah Tani, Kab. Cirebon. Desa yang berada di perbatasan antara Kota dengan Kabupaten Cirebon ini, telah berubah dari desa agraris menjadi desa industri kecil, di mana sebagian besar penduduknya bekerja dalam bidang industri kecil atau industri rumah tangga. Oleh karenanya Pemerintah Kabupaten Cirebon menobatkannya sebagai "Kampung Produktif". Respon masyarakat terhadap keberadaan kampung produktif ini baik walaupun para pengusaha UMKM meragukan apakah keberadaannya dapat meningkatkan pendapatan mereka (Dukat \& Wachdijono, 2017). Namun demikian, pada setiap perubahan tidak semua masyarakatnya akan mengalami proses perubahan yang sama, atau berubah dengan kecepatan yang sama dan mengalami akibat yang sama (Ismanto, Huda, \& Maulida, 2018). Para petani bunga tabur di Blok Kembang, Desa Gesik adalah salah satu contoh kelompok masyarakat yang lamban dalam merespon perubahan lingkungannya.

Di masa lalu, sekitar tahuan 1980-an, Blok Kembang pernah mengalami kejayaannya sebagai produsen bunga tabur dan melati ronce yang dipasarkan ke berbagai kota besar seperti Bandung dan Jakarta. Bunga tabur dan melati ronce umumnya digunakan pada acara-acara pernikahan, ziarah kubur, dan berbagai upacara adat lainnya. Namun demikian, seiring berjalannya waktu, muncul pesaing dari wilayah lain, baik di Kabupaten Cirebon maupun di luar Kab. Cirebon. Hal ini menyebabkan omset penjualan semakin menurun. Selain itu, alih fungsi lahan yang semakin meningkat menyebabkan lahan yang tersedia untuk budidaya bunga tabur semakit terbatas. Mengingat jenis tanaman yang diusahakan bukan dari kelompok tanaman pangan, maka perhatian dari Pemerintah Daerah juga tidak mereka peroleh.

Permasalahan yang muncul di petani bunga tabur adalah lahan yang digunakan bukan milik sendiri, melainkan sewa. Namun, lahan yang dapat disewa juga semakin terbatas dan penuh dengan 
ketidakpastian. Selain itu, pasar bunga tabur juga semakin terbatas yaitu hanya pada pasar-pasar di Kota Cirebon. Dalam hal pemasaran, permasalahan yang ditemukan sama dengan yang ditemukan pada para pedagang bunga segar di Surabaya, yaitu masalah dalam bidang produksi, manajemen, dan pemasaran (Oktaviana \& Hendarto, 2018).

Penerapan teknologi modern dan pasar yang mengutamakan efisiensi menyebabkan para petani kehilangan kesempatan untuk berusaha tani. Oleh karenanya para petani perlu lebih diberdayakan agar usaha taninya lebih efisien sehingga dapat meningkatkan produktivitas lahan dan pendapatannya (Elizabeth, 2017). Petani bunga tabur di Blok Kembang yang masih intens berusaha tani bunga tabur secara terus menerus hanya tinggal tiga orang, yang masing-masing memproduksi jenis tanaman yang berbeda. Walaupun ada beberapa orang petani lain yang berusaha tani bunga tabur, namun hanya bersifat musiman. Teknik bercocok tanam yang dilakukan masih tradisional dan belum intensif. Lahan yang sempit menyebabkan usaha tani mereka tidak efisien sehingga pendapatannya rendah (Mamondol \& Sabe, 2016). Oleh karena itu perlu upaya lain untuk meningkatkan pendapatan mereka. Inovasi yang akan diterapkan perlu mempertimbangkan kondisi sosial ekonomi mereka. Hal ini disebabkan karena tingkat adopsi inovasi akan dipengaruhi oleh faktor-faktor sosial dan ekonomi petani (Bananiek \& Abidin, 2013).

Solusi yang ditawarkan untuk meningkatkan pendapatan petani bunga taburdiBlokKembang Desa Gesik adalah dengan mensosialisasikan perbaikan teknik budidaya serta diversifikasi usaha untuk perluasan pasar. Tujuannya adalah meningkatkan keterampilan para petani dalam usahatani bunga tabur dengan berbagai alternatif produk.

\section{METODE}

Pada program kemitraan masyarakat ini digunakan metode pelatihan dan pendampingan. Metode pelatihan terdiri dari penyuluhan dan demonstrasi teknik budidaya dan perbanyakan tanaman hias, teknik pembuatan lilin aromaterapi dan pemasaran bunga tabur. Pendampingan dilakukan untuk budidaya bunga kingkong (Impatiens balsamina) di lahan, perbanyakan tanaman soka (Ixora spp.) dan mawar (Rosa spp.) dalam polybag. Tiga jenis tanaman tersebut dipilih karena merupakan tanaman yang biasa diusahakan mereka dan pasarnya sudah tersedia. Untuk mengupayakan jenis tanaman lain mereka tidak bersedia karena khawatir akan kesulitan memasarkannya.

Kelompok sasaran kegiatan ini adalah para petani bunga tabur, ibu-ibu anggota PKK Desa
Gesik, dan anggota masyarakat lain yang berminat dalam usaha tanaman hias. Pelatihan budidaya dan teknik perbanyakan bunga tabur dilakukan pada tanggal 20 - 21 Juli 2019 di Wisma Melati Blok Kembang, yang diikuti oleh 27 orang peserta. Peserta pelatihan terdiri dari para petani bunga tabur, ibu-ibu anggota Kelompok Wanita Tani(KWT) dan TPPKK Desa Gesik. Selain itu juga dilakukan pembuatan demonstrasi plot (demplot) untuk budidaya tanaman kingkong serta pembuatan bibit tanaman soka dan mawar di polybag. Untuk demplot, pemeliharaannya dilakukan bersama dengan para petani setempat.

\section{HASIL DAN PEMBAHASAN}

\section{Pelatihan Budidaya dan Perbanyakan Tanaman Hias}

Kegiatan ini bertujuan untuk meningkatkan pengetahuan dan keterampilan petani dalam budidaya bunga tabur dan perbanyakan tanaman. Selama ini petani melakukan pemeliharaan sebatas penyiraman, pemupukan, dan penyiangan. Para petani bunga soka umumnya tidak melakukan pemangkasan, selain untuk keperluan panen. Namun, para petani mawar terbiasa melakukan pemangkasan pada waktu-waktu tertentu untuk mengatur pembungan agar bunga muncul pada saat permintaan pasar meningkat. Materi penyuluhan yang diberikan terdiri dari teknik budidaya yang baik dan perbanyakan tanaman secara vegetatif dan generatif. Para petani peserta pelatihan umumnya lebih antusias dibandingpara ibu-ibu anggota KWT maupuan TP PKK Desa Gesik, karena mereka membandingkan antara pengalaman mereka di lapangan dengan materi yang disampaikan para nara sumber. Ketika terjadi perbedaan pendapat, alasan mereka sama, sudah terbiasa dan selama ini tidak ada masalah.

Para petani umumnya menyadari bahwa usahatani bunga tabur tidak dapat berkembang kecuali dengan perluasan lahan. Namun mereka juga menyadari bahwa hal itu tidak mungkin terjadi di Blok Kembang, Desa Gesik. Alternatif usaha yang ditawarkan, yaitu pembuatan bibit tanaman hias, disambut baik sebagai usaha sampingan karena tidak dapat segera dipasarkan. Kegiatan pembibitan tanaman sebenarnya biasa dilakukan oleh petani bunga mawar, namun tujuannya sebatas dalam rangka peremajaan tanaman saja. Ranting yang dipotong kemudian ditanam di lahan yang sudah diolah tanpa perlakuan apapun.

Pada kegiatan pengabdian ini diperkenalkan manfaat lain dari batang atau ranting tanaman, yaitu untuk perbanyakan tanaman dengan tujuan menghasilkan bibit tanaman hias yang dapat dipasarkan. Salah satu teknik budidaya yang diperkenalkan adalah penggunaan zat pengatur 
tumbuh (ZPT) berbahan aktif auksin. Kegunaan ZPT ini adalah untuk mempercepat tumbuhnya akar (Suprapto, 2004), sehingga setek akan lebih cepat tumbuh menjadi tanaman muda. Perendaman bahan setek mawar dalam auksin alami urin sapi selama 15 menit memberikan pengaruh terbaik terhadap pertumbuhan tunas dan akarnya (Hafizah, 2014). Pada setek jarak pagar, selain jumlah ruas penggunaan ZPT Rootone F juga berpengaruh nyata terhadap pertumbuhan setek (Dukat, Wahyuni, \& Prasetyo, 2017).

Hal lain yang merupakan teknik budidaya baru bagi mereka adalah budidaya tanaman hias di dalam polybag, karena selama ini mereka menanam tanaman di lahan. Budidaya di polybag mempunyai keterbatasan, karena ruang untuk pertumbuhan akar terbatas. Oleh karenanya komposisi media tanam yang digunakan akan sangat berpengaruh terhadap pertumbuhan tunas pada setek. Pada bibit mikro kentang, media tanam yang terdiri dari tanah, arang sekam dan pupuk kandang dengan perbandingan 1:1:1 memberikan pengaruh terbaik terhadap pertumbuhan akar (Jon, 2018). Sementara pada berbagai klon mawar mini, komposisi media tanam yang terdiri dari arang sekam dan kompos daun bamboo memberikan pengaruh yang terbaik terhadap pertumbuhan bibit mawar (Rosana, 2011). Pada kegiatan pengabdian ini, media tanam yang digunakan adalah campuran tanah, pupuk kandang, dan sekam padi dengan perbandingan 1:1:1. Komposisi media tanam ini dipilih karena bahan-bahannya mudah ditemukan di lokasi tempat pengabdian.

Bahan setek mawar dan soka yang sudah disiapkan, dipotong miring $45^{\circ}$ pada ujung bawahnya untuk memperluas perrmukaan tempat tumbuhnya akar (Gambar 1) kemudian direndam dalam larutan ZPT dengan konsentrasi $2 \mathrm{~g}$ dalam $10 \mathrm{ml}$ air. Perendaman dilakukan selama 15 menit, kemudian bahan setek ditiriskan dan siap ditanam. Media tanam yang terdiri dari tanah yang sudah dicampur pupuk kandang dan sekam dicampur dengan perbandingan seperti yang telah ditentukan. Media tanam kemudian dimasukkan ke dalam polybag dan bibit tanaman kemudian ditanam di dalamnya (Gambar 2). Setelah itu bibit disiram dan ditempatkan di tempat yang teduh.

Pemeliharaan dilakukan bersama di antara para peserta. Mereka membagi kelompok dan mengatur jadwal untuk penyiraman dan pemeliharaan lainnya. Evaluasi dan monitoring dilakukan sekali dalam seminggu selama tiga minggu. Pada minggu ketiga telah nampak tunas yang muncul pada sebagian (45\%) bibit, terutama mawar (Gambar 4). Hal ini menunjukkan bahwa keterampilan para peserta sudah cukup baik. Mengingat bahwa ini pertama kali bagi mereka menanam tanaman di polybag.

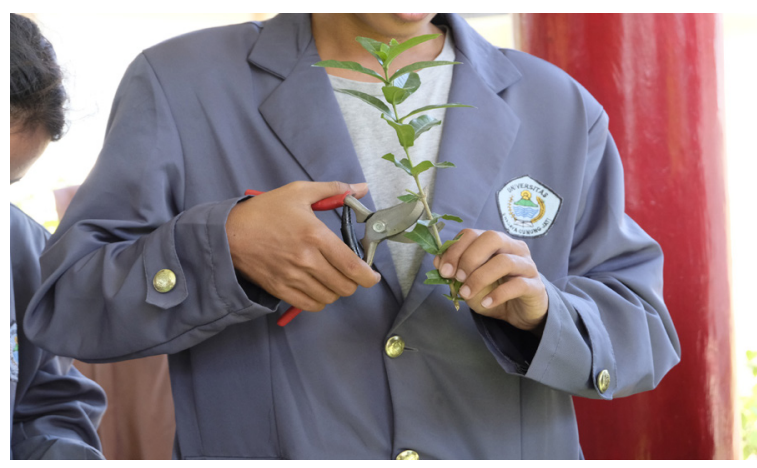

Gambar 1. Persiapan bahan untuk bibit soka

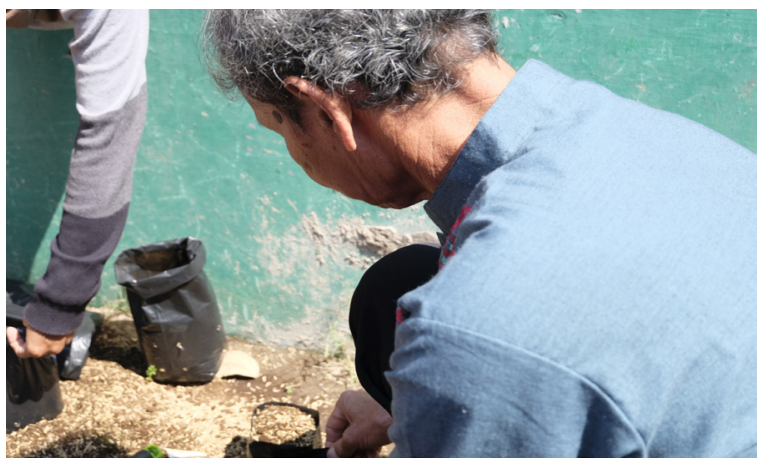

Gambar 2. Mengisi polybag dengan campuran media tanam

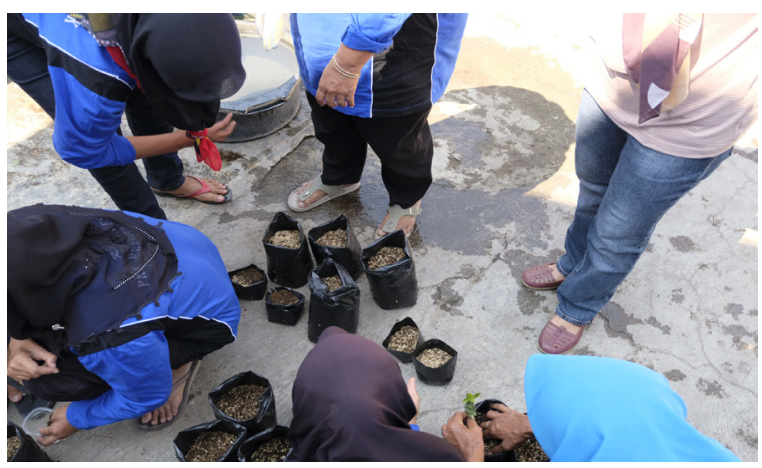

Gambar 3. Menanam bibit dalam polybag

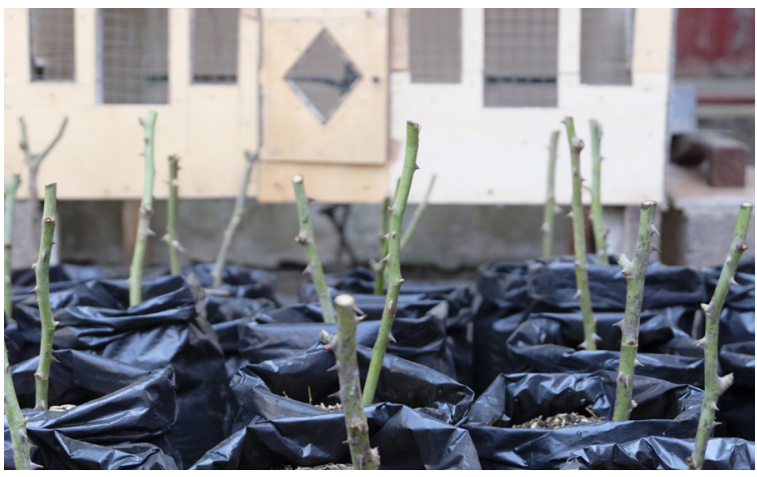

Gambar 4. Bibit mawar yang sudah mulai tumbuh

\section{SIMPULAN}

Berdasarkan evaluasi selama kegiatan berlangsung, dapat disimpulkan bahwa para peserta pelatihan cukup tertarik serta sudah menguasai keterampilan membuat bibit tanaman hias mawar dan soka. Namun demikian, keterampilan ini perlu ditingkatkan 
mengingat tingkat keberhasilan pertumbuhan setek masih rendah. Hal ini dapat dilakukan dengan melatihnya secara terus menerus. Selain itu, untuk menjadikan keterampilan tersebut sebagai usaha perlu dilakukan pendampingan dan mencarikan pasarnya.

\section{UCAPAN TERIMAKASIH}

Ucapan terima kasih disampaikan kepada Kementerian Riset, Teknologi dan Pendidikan Tinggi yang telah membiayai kegiatan ini melalui Hibah Pengabdian Kepada Masyarakat KompetitifNasional untuk skema Program Kemitraan Masyarakat tahun 2019.

\section{DAFTAR PUSTAKA}

Bananiek, S., \& Abidin, Z. (2013). Faktor-Faktor Sosial Ekonomi yang Mempengaruhi Adopsi Teknologi Pengelolaan Tanaman Terpadu Padi Sawah di Sulawesi Tenggara. Jurnal Pengkajian Dan Pengembangan Teknologi Pertanian, 16(2), 111-121.

Dukat, \& Wachdijono. (2017). Analisis Respon Masyarakat dan Aparat Pemerintah Desa terhadap Keberadaan Kampung Produktif di Desa Gesik Kecamatan Tengah Tani Kabupaten Cirebon. In A. Y. Isyanto, Z. Noormansyah, T. I. Noor, H. D. Rochdiani, D. Sufyadi, D. L. Hakim, ... D. A. Farid (Eds.), Seminar Nasional Hasil Penelitian Agribisnis I FP UNIGAL (pp. 528-536). Ciamis: Program Studi Agribisnis Fakultas Pertanian Universitas Galuh Ciamis. Retrieved from http://repository.unigal.ac.id/ handle/123456789/39
Dukat, Wahyuni, S., \& Prasetyo, M. (2017). Pengaruh Panjang Stek dan Konsentrasi Rootone F Terhadap Pertumbuhan Stek Jarak Pagar (Jatropha curcas L .). AGROVIGOR, 10(2), 128-132.

Elizabeth, R. (2017). Fenomena Sosiologis Metamorphosis Petani: ke Arah Keberpihakan pada Masyarakat Petani di Pedesaan yang Terpinggirkan Terkait Konsep Ekonomi Kerakyatan. Forum Penelitian Agro Ekonomi, 25(1), 29. https://doi.org/10.21082/fae. v25n1.2007.29-42

Hafizah, N. (2014). Pertumbuhan Stek Mawar (Rosa Damascena Mill.) pada Waktu Perendaman dalam Larutan Urine Sapi. Ziraa'ah Majalah Ilmiah Pertanian, 39(3), 129-135.

Ismanto, K., Huda, M., \& Maulida, C. (2018). Transformasi Masyarakat Petani Mranggen Menuju Masyarakat Industri. Jurnal Penelitian, 9(1), 35-48. https://doi. org/10.28918/jupe.v9i1.129

Jon, E. (2018). Pengaruh Media Tanam Terhadap Pertumbuhan Setek Mikro Kentang Varietas Granola (Solanum tuberosum L.). Edubiotik, 3(1), 26-33.

Mamondol, M. R., \& Sabe, F. (2016). Pengaruh Luas Lahan Terhadap Penerimaan, Biaya Produksi, dan Pendapatan Usahatani Padi Sawah di Desa Toinasa Kecamatan Pamona Barat. Jurnal Envira, 1(2), 48-59.

Oktaviana, S., \& Hendarto, T. (2018). Teknologi Tepat Guna Bagi Kelompok Penjual Bunga Segar. Jurnal ABM Mengabdi, 5, 111-122. Retrieved from https:// scholar.google.co.id/scholar?hl=id\&as 